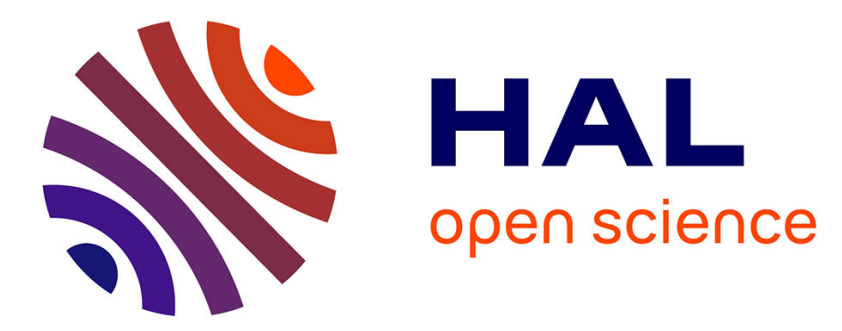

\title{
Relationship Between the Local Structures of Titanium Oxide Photocatalysts and their Reactivities - XAFS, UV, Photoluminescence and Photoreaction Investigations
}

\author{
Y. Ichihashi, H. Yamashita, M. Anpo
}

\section{To cite this version:}

Y. Ichihashi, H. Yamashita, M. Anpo. Relationship Between the Local Structures of Titanium Oxide Photocatalysts and their Reactivities - XAFS, UV, Photoluminescence and Photoreaction Investigations. Journal de Physique IV Proceedings, 1997, 7 (C2), pp.C2-883-C2-885. 10.1051/jp4:1997265 . jpa-00255348

\section{HAL Id: jpa-00255348 https://hal.science/jpa-00255348}

Submitted on 1 Jan 1997

HAL is a multi-disciplinary open access archive for the deposit and dissemination of scientific research documents, whether they are published or not. The documents may come from teaching and research institutions in France or abroad, or from public or private research centers.
L'archive ouverte pluridisciplinaire HAL, est destinée au dépôt et à la diffusion de documents scientifiques de niveau recherche, publiés ou non, émanant des établissements d'enseignement et de recherche français ou étrangers, des laboratoires publics ou privés. 


\title{
Relationship Between the Local Structures of Titanium Oxide Photocatalysts and their Reactivities - XAFS, UV, Photoluminescence and Photoreaction Investigations
}

\author{
Y. Ichihashi, H. Yamashita and M. Anpo \\ Department of Applied Chemistry, Osaka Prefecture University, Gakuen-cho 1-1, Sakai, Osaka 593, \\ Japan
}

\begin{abstract}
The liquid-phase photocatalytic oxidation of 1-octanol in oxygenated acetonitrile on highly dispersed titanium oxide catalysts anchored onto transparent Vycor glass was compared with that obtained on the standard $\mathrm{TiO}_{2}$ powder. The isolated titanium oxide species anchored onto transparent Vycor glass are responsible for its high photocatalytic activity both in the present liquid-phase oxidation of 1-octanol and in previously described gas-phase reactions. And also the photocatalytic degradation of 2-propanol diluted in water was demonstrated on the titanium oxide catalysts highly dispersed onto Vycor glass which were prepared by $\mathrm{Ti}$ ions implantation method. The specific photocatalytic activity per unit weight of titanium oxide of the highly dispersed catalyst was much higher than that for the $\mathrm{TiO}_{2}$ powder. The photoluminescence, UV absorption and XAFS studies indicated that the charge transfer excited state of the highly dispersed isolated tetrahedral titanium oxide species play a significant role in the liquid-phase photocatalytic reactions.
\end{abstract}

\section{INTRODUCTION}

The design of highly efficient and selective photocatalytic systems that work with no loss of energy for applications in reducing global atmospheric pollution and/or degradation of various toxic compounds in aqueous solutions is of special interest and one of the most desirable and vital goals in environmental-friendly-catalyst research [1]. Although the utilization of the extremely small semiconductors particles as photocatalysts has attracted a great deal of attention especially for environmental applications $[2,3]$. Especially, the $\mathrm{TiO}_{2}$ photocatalysts are known as the semiconductors which have high stabilities and highly photocatalytic activities. The catalytic effectiveness of small semiconductors can vary greatly with the physical properties of the samples [4,5]. In addition, in practical applications, the separation of the $\mathrm{TiO}_{2}$ particles from the contaminated solution constitutes a major difficulty. The design of active photocatalysts anchored on or inside transparent supports or embedded onto transparent materials is greatly desired [6-9]. In this study, liquid-phase photocatalytic oxidation of 1-octanol by titanium oxide anchored on porous Vycor glass was compared with that obtained on small particle $\mathrm{TiO}_{2}$ powders. In addition, we deal with the preparation and characterization of the highly dispersed titanium oxide species which were implanted onto Vycor glass and the successful utilization of these catalysts for the photocatalytic degradation of 2-propanol diluted in water.

\section{EXPERIMENTAL}

The $\mathrm{TiO}_{2}$ catalyst was supplied by the Catalysis Society of Japan as a standard reference catalyst (JRC-TIO-4 : surface area $\approx 50 \mathrm{~m}^{2} / \mathrm{g}$, band gap $\approx 3.50 \mathrm{eV}$, purity $>99.5 \%$ ). Titanium oxide anchored onto Vycor glass (an.Ti/VG) was prepared by reaction of $\mathrm{TiCl}_{4}$ with the surface $\mathrm{OH}$ groups of a transparent porous Vycor glass (Corning code 7930, BET surface area 150 $\mathrm{m}^{2} \mathrm{~g}^{-1}$ ) in the gas phase at $473 \mathrm{~K}$, followed by treatment with $\mathrm{H}_{2} \mathrm{O}$ vapor to hydrolyze the anchored compounds. The anchoring procedures were repeated three to five times to increase the number of surface layers of the anchored titanium oxide on the Vycor glass (an.Ti/VG-3 and an.Ti/VG-5). The titanium contents of the anchored catalysts were an.Ti/VG-1: 0.17, an.Ti/VG-3: 0.94 and an.Ti/VG-5: $1.6 \mathrm{wt} \%$ as Ti contents, respectively. Titanium oxide catalysts implanted onto Vycor glass (im.Ti/VG) with different Ti contents $\left(4.3 \times 10^{-7}, 8.7 \times 10^{-7}, 17.3 \times 10^{-7} \mathrm{~mol} / \mathrm{cat} . \mathrm{g}\right)$ were prepared by the metal ion-implantation method (acceleration voltage: $100 \mathrm{keV}$ ). The catalysts were treated with $\mathrm{O}_{2}$ at $723 \mathrm{~K}$ before use.

XAFS spectra (XANES and EXAFS) were obtained at the BL-7C facility of the Photon Factory at the National Laboratory for High-Energy Physics, Tsukuba. Si(111) double crystals were used to monochromatize the X-rays from the 2.5 $\mathrm{GeV}$ electron storage ring. The Ti K-edge absorption spectra were recorded in the fluorescence mode for the anchored catalysts and in transmission mode for the $\mathrm{TiO}_{2}$ powder at $295 \mathrm{~K}$. Fourier transformation were performed on $k^{3}$-weighted EXAFS oscillations in the range of 3-10 $\AA^{-1}$.

The photocatalytic oxidation of 1-octanol was carried out using the catalysts (JRC-TIO-4: $25 \mathrm{mg}$, an.Ti/VG: $50 \mathrm{mg}$ ) in the 1-octanol $(0.5 \mathrm{mmol})$-acetonitrile $(25 \mathrm{ml})$ solution at $300 \mathrm{~K}$. $\mathrm{O}_{2}$ was bubbled and catalyst underwent UV irradiation at around $300 \mathrm{~nm}$. The im.Ti/VG catalyst $(150 \mathrm{mg})$ in the aqueous solution of 2 -propanol $\left(2.6 \times 10^{-3} \mathrm{~mol} / \mathrm{l}\right)$ was irradiated $(\lambda>280 \mathrm{~nm})$ at $300 \mathrm{~K}$ using UV-light under bubbling of $\mathrm{O}_{2}$ in the system. The products were analyzed by the gas chromatography. 


\section{RESULTS AND DISCUSSION}

\subsection{Titanium oxide anchored on Vycor glass}

UV-irradiation of several Ti/VG catalysts suspended in oxygenated acetonitrile led to the photocatalytic oxidation of 1 octanol to 1-octanal. No products were detected in the dark under the same reaction conditions. The photocatalytic oxidation of 1-octanol on highly dispersed titanium oxide catalysts anchored onto transparent Vycor glass was compared with that obtained on the $\mathrm{TiO}_{2}$ powder. Figure 1 shows the time profile for the conversion of 1-octanol under UV-irradiation at around $300 \mathrm{~nm}$. Among these an.Ti/VG catalysts, an.Ti/VG-1 exhibits the highest photocatalytic activity, although an.Ti/VG-1 has the lowest $\mathrm{TiO}_{2}$ content. Among an.Ti/VG catalysts, the photocatalytic activity of the an.Ti/VG-1 catalyst is much higher than that of an.Ti/VG-3 or an.Ti/VG-5. Increasing the number of Ti-O layers of the an.Ti/VG catalysts caused the photocatalytic activity of the titanium oxide species (per unit weight of Ti) to decrease remarkably.

Upon the excitation of the an.Ti/VG-5 catalyst with the UV-light at around $280 \mathrm{~nm}$ these anchored catalysts exhibited an intense photoluminescence at around $490 \mathrm{~nm}$. As reported in previous papers [6-9], the absorption of light brings about an electron transfer from the lattice oxygen to the surface-accessible titanium ion, resulting in the formation of a trapped hole $\left(\mathrm{OL}_{\mathrm{L}}{ }^{-}\right)$and a trapped electron $\left(\mathrm{Ti}^{3+}\right)$. On the other hand, the photoluminescence intensities of the an.Ti/VG-3 and an.Ti/VG-5 catalysts were very weak. Such behavior indicates that highly dispersed isolated titanium oxide species exist only on an.Ti/VG-1, whereas they exist as aggregates on an.Ti/VG-3 and an.Ti/VG-5.

Figure 2 shows the XANES and FT-EXAFS spectra of the an.Ti/VG catalysts. Although the bulk $\mathrm{TiO}_{2}$ exhibits three small pre-edge peaks in its XANES spectrum, the an.Ti/VG-1 catalyst exhibits only a single and intense pre-edge peak similar to that of tetrahedrally coordinated titanium tetra-i-propoxide. This observation indicates the presence of tetrahedrally coordinated titanium oxide species on the surface of the an.Ti/VG-1 catalyst. The FT-EXAFS spectra of the an.Ti/VG-1 (Fig. 2-a') exhibit only Ti-O peaks, indicating the presence of an isolated titanium oxide species. With an.Ti/VG-3 and an.Ti/VG-5 catalysts, the pre-edge peak becomes weaker in the XANES spectra and other peaks attributed to neighboring titanium atoms (Ti-O-Ti) appeared in the FT-EXAFS spectra. These results indicate that highly dispersed isolated tetrahedral titanium oxide clusters were anchored on the Vycor glass and that an increase in the number of Ti-O layers led to aggregation of the isolated titanium species. The isolated titanium oxide species on the an.Ti/VG-1 are responsible for its high photocatalytic activity both in the present liquid-phase oxidation of 1-octanol and in previously described gas-phase reactions [6-9]. We consider that the charge transfer excited state of isolated titanium oxide in a tetrahedral coordination complex, $\left(\mathrm{Ti}^{3+}-\mathrm{O}^{-}\right)^{*}$, play a significant role for the liquid-phase photocatalytic reaction.

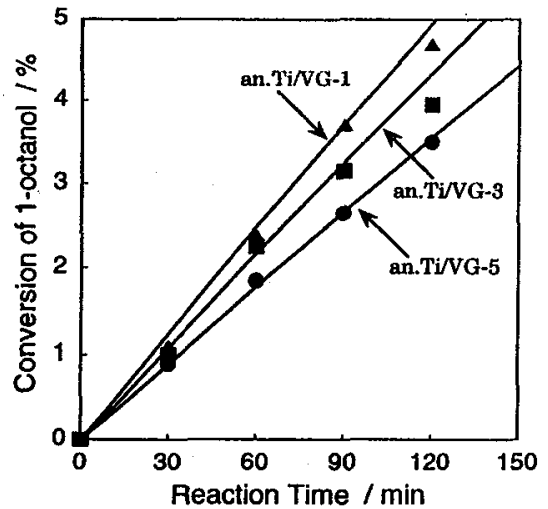

Figure 1: Reaction profile for the photocatalytic oxidation of 1-octanol over titanium oxide anchored on Vycor glass under irradiation at around $300 \mathrm{~nm}$
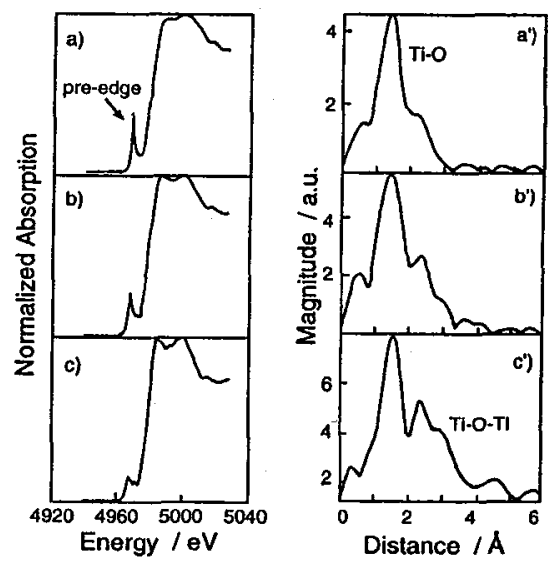

Figure 2: The Ti K-edge XANES spectra (left) and FTEXAFS spectra (right) of an.Ti/VG-1 (a, $\left.a^{\prime}\right)$, an.Ti/VG-3 (b, b'), and an.Ti/VG-5 (c, c') catalysts.

\subsection{Titanium oxide implanted on Vycor glass}

The photocatalytic degradation of 2-propanol diluted in water to form 2-propanal and $\mathrm{CO}_{2}$ was investigated on the titanium oxide catalysts dispersed onto VG prepared by an ion-implantation method (im.Ti/VG). As shown in Fig. 3, the specific photocatalytic activities of these im.Ti/VG photocatalysts are found to be much higher than that of small particles of $\mathrm{TiO}_{2}$ powders. The specific photocatalytic activity of the im.Ti/VG photocatalysts is remarkably enhanced in the regions of lower Ti contents. 
Figure. 4 shows the Ti K-edge XAFS spectra of these im.Ti/VG photocatalysts. These catalysts exhibit a single and intense preedge peak in the XANES spectra, indicating that the Ti/VG catalysts with the lower Ti contents include the titanium oxide species in a tetrahedral coordination. The FT-EXAFS spectrum of the im.Ti/VG catalyst of lowest Ti contents exhibits only a Ti-O peak, indicating the presence of an isolated titanium oxide species. With increasing the Ti contents in the im.Ti/NG catalysts, the pre-edge peak becomes weaker in the XANES spectra and other peaks attributed to neighboring titanium atoms (Ti-O-Ti) appear in the FT-EXAFS spectra. Furthermore, titanium oxide catalysts dispersed onto VG prepared by the ion-implantation method (im.Ti/VG) exhibited large blue shifts in the UV absorption band, its extent depending on the Ti contents. These blue shifts are associated with the presence of the high dispersion of titanium oxide species in the im.Ti/VG in good agreement with the results shown in the XAFS spectra.

These results indicate that the im.Ti/VG photocatalysts are effective photocatalysts for the liquid-phase reactions and the application of the metal ion-implantation method is useful and promising for the preparation of the highly active glass-like photocatalysts.

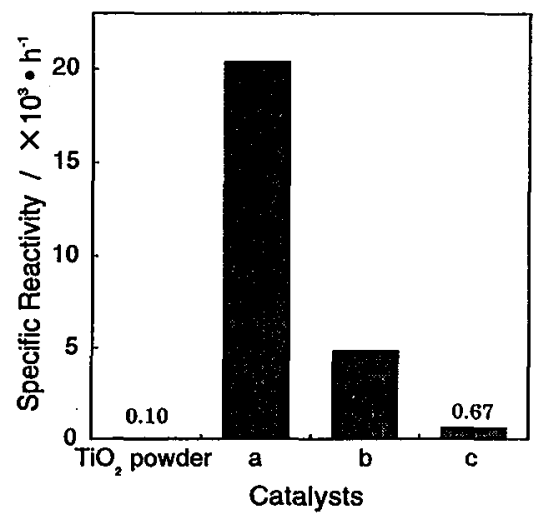

Figure 3: Effect of the amounts of Ti ions implanted on the specific photocatalytic reactivities of the $\mathrm{im} . \mathrm{Ti} / \mathrm{VG}$ photocatalysts for the degradation of 2-propanol at $295 \mathrm{~K}$. Amounts of implanted Ti ions: (a) 4.3 , (b) 8.7 , (c) $17.3 \times 10^{-7}$ mol/cat.-g. Ion acceleration voltage: $100 \mathrm{keV}$.
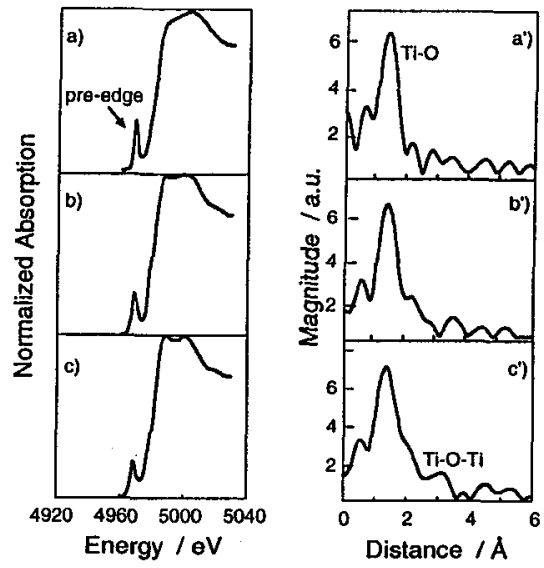

Figure 4: The Ti K-edge XANES (a-c) and FT-EXAFS (a'-c') spectra of im.Ti/VG photocatalysts. Amounts of implanted $T i$ ions: (a, a') 4.3, (b, b') 8.7 , (c, c') $17.3 \times 10^{-7} \mathrm{~mol} / \mathrm{cat} . \mathrm{g}$. Ion acceleration voltage: $100 \mathrm{keV}$.

\section{CONCLUSION}

Anchoring and ion-implantation are attractive methods for preparing highly active titanium oxide catalysts highly dispersed on the transparent support such as porous Vycor glass. The titanium oxide species exist in a tetrahedral coordinate in these catalysts and their charge transfer excited state, $\left(\mathrm{Ti}^{3+}-\mathrm{O}^{-}\right)^{*}$, plays a significant role as a key active species in liquidphase photocatalytic reactions. These photocatalysts are effective for the separation of the photocatalysts from the contaminated solution and are suitable for the practical utilization of photocatalysts.

\section{References}

[1] M. Anpo and H. Yamashita, in Surface Photochemistry, M. Anpo Ed. (John Willey \& Sons, London, 1995) pp.117-164.

[2] N. Serpone, and E. Pelizzetti, "Photocatalysis: Fundamentals and Applications" (John Willey \& Sons, New York, 1989).

[3] D. F. Ollis, and H. Al-Ekabi, "Photocatalytic Purification and Treatment of Water and Air" (Elsevier, Amsterdam, 1993).

[4] M. Anpo, T. Shima, S. Kodama, and Y. Kubokawa, J. Phys. Chem., 91 (1987) 4305-4310.

[5] H. Yamashita, H. Nishiguchi, N. Kamada, M. Anpo, Y. Teraoka, H. Hatano, S. Ehara, K. Kikui, L. Palumisano, A. Sclafani, M. Schiavello and M. A. Fox, Res. Chem. Intermed., 20 (1994) 815-823.

[6] M. Anpo, N. Aikawa, Y. Kubokawa, M. Che, C. Louis, and E. Giamello, J. Phys. Chem., 89 (1985) 5017-5021.

[7] M. Anpo and K. Chiba, J. Mol. Catal., 74 (1992) 207-212.

[8] H. Yamashita, Y. Ichihashi, M. Harada, G. Stewart, M. A. Fox, and M. Anpo, J. Catal., 157 (1996) 97-101.

[9] H. Yamashita, Y. Ichihashi, M. Anpo, C. Louis, and M. Che, J. Phys. Chem., in press. 